\title{
Ideal and Reality: The Reform of Juvenile Sealed Criminal Records in China
}

\author{
Wenqing Yang, Xiaozheng Lei \\ Criminal Legal Science, Beijing Normal University, Beijing, China \\ Email: na.jiang@bnu.edu.cn
}

How to cite this paper: Yang, W. Q., \& Lei, X. Z. (2019). Ideal and Reality: The Reform of Juvenile Sealed Criminal Records in China. Chinese Studies, 8, 210-221. https://doi.org/10.4236/chnstd.2019.84017

Received: October 23, 2019

Accepted: November 26, 2019

Published: November 29, 2019

Copyright $\odot 2019$ by author(s) and Scientific Research Publishing Inc. This work is licensed under the Creative Commons Attribution International License (CC BY 4.0).

http://creativecommons.org/licenses/by/4.0/

\section{cC) (i) Open Access}

\begin{abstract}
Two-way protection is a special concept of juvenile justice. The connotation of this concept is to protect minors while taking the protection of social and public interests into account. Under this concept, the sealed criminal records system should balance the protection of minors and social defense effectively. However, the current system of juvenile sealed criminal records in China has some problems, such as improper disclosure of criminal information, rigid scope of sealed, hindering the employment of juveniles etc., which deviates from the concept of two-way protection principle. From the perspective of the principle of two-way protection, this paper explores the state-should-be of the system and analyzes the problems in judicial practice, and then perfects the current system from the aspects of concept correction and system docking, in order to make the system protect the interests of juvenile offenders to the greatest extent and take the protection of social interests into account.
\end{abstract}

\section{Keywords}

Two-Way Protection, Interests of Juvenile Offenders, Public Safety, Sealed Criminal Record

\section{Introduction}

Cesare Bonesana Beccaria (1738-1794) once said: "It is not the intensity, but the extent of a punishment which makes the greatest impression on the human soul. Because our sensibility is more easily and lastingly moved by minute but repeated impressions than by a sharp but fleeting shock" (Beccaria, Huang feng, Trans., 2017). Even if criminal penalties are completed, they will still face various forms of exclusion and mental suffering. The more information that law enforcement collects and shares about suspected criminals and actual offenders, the easier it is to identify and discriminate against those marked individuals and 
socially isolate them. This, it turns out the increase in recidivism, therefore undermining the public safety goal that drives accessible criminal records (Lapp, 2016). Especially for growing minors, the psychological impact of criminal records on them is more intense; the experience of punishment makes it difficult for them to establish normal interpersonal relationships. The "label" of the perpetrator will torment his mind and spirit, delay or even hinder the process of their return to society. In order to change the above situation, article No. 275 of the Code of Criminal Procedure (2012 Amendment) provides that: "Where a juvenile has not attained the age of 18 when committing a crime and is sentenced to fixed-term imprisonment of five years or a lighter punishment, the related criminal records shall be sealed for preservation. The sealed criminal records may not be provided to any entity or individual, unless as needed for a judicial authority to handle cases or for consultation by relevant entities according to relevant state provisions. "At this point, China's juvenile sealed criminal record system has been formally established, which conforms to the historical trend of juvenile justice, takes the particularity of minors into account and is of great significance for the rescue of minors who have commit crime." In addition, in order to balance public security, China's sealed criminal records adopt double restrictions. On the one hand, the sealed criminal records are only applied to minors sentenced to a penalty of up to 5 years' imprisonment; On the other hand, the judicial authority can search the record when they need to handle cases or the entities can inquire the record according to relevant state provisions. However, in judicial practice, there are many deviations between the operation of the system and the original intention of legislation, and the operation effect is not satisfactory. This paper attempts to analyze the state-should-be and the practical state of the system, and furthermore put forward some improvement suggestions.

\section{The State-Should-Be of the Juvenile Sealed Criminal Records}

The juvenile sealed criminal records are a juvenile justice system established by the legislature of our country, which is based on the principle of two-way protection. As the basic concept of juvenile justice, which originated from the United Nations minimum standards for juvenile justice, article 1.4 of the Convention provides: "Juvenile justice shall be conceived as an effective means of contributing to the protection of young and the maintenance of a peaceful order in society." The basic connotation of the concept of two-way protection includes two aspects: first, the principle emphasizes the importance of protecting minors (Zhao, 2013). On the one hand, the minor's mind is not fully mature and susceptible to external influences. In addition, Juveniles often cannot appreciate the long-term consequences of their actions and struggle to control their raging hormones, These biological factors often lead to juveniles' irresponsible behavior (Wieder, 2014). On the other hand, minors have high plasticity, if appropriate guidance, education and correction are given to them; it is relatively easy to help 
them return to society. In addition, the causes of juvenile delinquency, except themselves, state, society, family and so on should bear a relatively large responsibility. For example, social factors such as disharmony of family relations, misconduct of parents, incorrect mode of education, improper management system and so on. Secondly, the principle also means maintaining the long-term stability of society. It should be emphasized that although juvenile delinquency are more special, even if the minor's crime have multiple causes, it cannot deny the side of their own will, so the individual responsibility of minors cannot be completely ignored. In addition, even if families, schools, societies and countries should hold the greater responsibility, it cannot be at the expense of public safety. After all, the protection of minors cannot go to extremes and endanger the sense of security of the citizens. From the point of view of two-way protection concept, the sealed criminal record system should satisfy the following requirements: firstly, "de-stigmatize" of juvenile offenders. The label of the offender will not only produce a normative evaluation, juvenile offenders will be subject to various restrictions at the legal level, but also it is difficult for the minor to engage in normal social activities, and encounter obstacles in education, employment and so on. The labelling effect may also make juvenile be isolated by social groups, so that they have to be associated with people in the same situation, which can easily lead to cross-infection and greatly increase the likelihood of recidivism. The first task in protecting the interests of minors is to help them "de-stigmatize" as much as possible, and the emphases of de-stigmatize should limit the source of labels and minimize the spread of juvenile crime information. Secondly, the "re-socialization" of juvenile offenders. Helping minors to reintegrate into society is also one of the basic requirements of the concept of two-way protection, because from the point of protecting minors' interests, providing education and employment opportunities for juvenile offenders help them to realize their own value and establish a sound personality. The re-socialization of juvenile offenders is also in line with the fundamental interests of society and is conducive to the long-term stability of society. Thirdly, the stability and harmony of social order are taken into account. Protecting the interests of society and maintaining social order is also one requirement of the concept of two-way protection. It is also an effective means to maintain social order by making some criminal information public, which can raise the public's awareness of prevention, and facilitate victims to take measures to prevent crime. Some habitual crimes, even if corrected through penalties or other educational measures, are difficult to cure the deviant behavior. Rather than pinning the hope of preventing harm on the actor's own control, it is better to provide the general public with access to criminal records so that they take measures to protect themselves. Therefore, the system of juvenile sealed criminal records is balanced by the public's right and the right of juvenile rehabilitation.

\section{The Practical State of Juvenile Sealed Criminal Records}

From more than six years of judicial practice, the juvenile sealed criminal records 
system neither conducive to rehabilitation nor effective for public safety. There are many deviations from its basic requirements, mainly manifested in the following three aspects:

\section{1) Early disclosure of sealed information}

The handling of the criminal case needs to be investigated by the investigation authorities, prosecuted by the public prosecutor's office, and then to the court. If criminal information is not effectively protected before the verdict, then sealed criminal record is virtually difficult to function. However, there are many cases of leaking information in the course of case processing in our country at present. Concretely Speaking, firstly, the lag in the sealed phase leads to the early disclosure of criminal information. The investigation stage and the prosecution stage do not protect the juvenile crime information in advance. The investigation organ is the first institution to know the relevant information of minors, although this stage has characteristics of secrecy and closure, if the investigators do not have the awareness to protect the information of minors, it may cause the spread of information. During the prosecution phase, defense attorney have access to case files. This stage also may involve mediation, conciliation and other procedures, which greatly increase the possibility for the public to be informed of the information of minors; Secondly, at the trial stage, although our country provides that minors are required to hear in camera, but the sentences are made public. The public judgment calls for the public reading of the verdict, while the formal judgment not only requires the description of the facts of the crime, but also the basic personal information of the accused, such as his name, gender, age and address. Such an approach would undoubtedly diminish the effect to be achieved in closed hearings. Thirdly, the improper operation of the relevant juvenile justice system leads to the improper disclosure of criminal information. Taking the particularity of minors into account, juvenile justice emphasizes that minors should be rehabilitated, find out the causes of their crimes, and help them correct, so when handling juvenile criminal cases, the people's court, the people's procuratorate, and the public security authority may investigate the growth, cause of crime, guardianship, education, and other aspects of the juvenile criminal suspect or defendant and community correction should be taken after the judgment to correct their improper behavior. These two systems take a positive approach to help minors to rehabilitate, but improper use does reveal a large amount of crime-related information. For example, the social investigation needs to ask the minor's neighbors, teachers, classmates, the neighborhood committee, the village council, and the more adequate the interview, the more comprehensive and true information obtained. But in the process of communication, it is easily to expand the information. Community correction requires juvenile offenders to abide by certain rules, participate in certain corrective activities, and ask specific personnel to ascertain the situation of minors, these methods will reveal the case information of juvenile offenders and their personal privacy to a certain extent; Fourthly, in order to attract attention and increase the amount of clicks, the media expose the crime information of the minor. For 
example, the sensational rape case of Li XX, "Chongqing girl child abuse case" and so on. And the influence of the media, the scope of information proliferation, will result in a large negative impact, which also means that the later sealed criminal record has actually lost its meaning.

\section{2) a heavier preference for social security}

There is a deep-seated idea of the presumption of guilt in our country, which holds the idea that the perpetrator "is a thief one day and a thief for Life". In addition, most people agree that restrictions on employment and education of persons with previous convictions can be allowed, which is a way of sacrificing the interests of a small number of people for the large number of people. In addition, in an era of heightened security concerns, easily available data, and increased criminal background checks, these records act as a substantial barrier to gainful employment and other opportunities (Selbin, McCrary, \& Epstein, 2018). More specifically, Employers concern during recruitment, schools also concerns when recruiting and considering whether to allow them to return to school, and public security organs that protect public safety have deep concerns about this part of the people, they take special measures to monitor and track their daily lives. However, the above actions are taking the social order into account, if strictly enforced will prevent the juvenile offenders from reintegrating into society. Concretely Speaking, Firstly, at present, there is an overly broad prohibition of employment in our country, which prevents minors from being employed. According to the preliminary statistical of relevant scholars, there are 51 provisions containing restrictions on the qualifications of practitioners, which only involve laws and regulations at the national level. If we take the implementation rules and rectification notices of various local administrative regulations and local administrative departments into account, the number of qualifications restrictions may not be calculated. Among the 51 laws and regulations, the Law on employment restrictions for ex-offenders can be divided into: lifetime prohibition and prescribed time limit. The former is, for example, article 24th of the Civil Service Law, article 11th of the Law on Prosecutors, and the latter, such as article 10th of the Accountants Act. According to the type of crime restricted by criminal record, it can be divided into: all types of crime and specific types of crime, the former such as Article 3 of the Military Service Law, the latter article 147th of the Companies Law, From the above-mentioned law, we can see that the types of restrictions on employment in our country are very extensive, involving all walks of life, such as accountants, securities practitioners, judges, prosecutors, auctioneers, civil servants, and even tour guides, publishers, surveyors, valuers and so on. Most of these occupations adopt the "one-size-fits-all" model, prohibiting criminals from stepping in for life. What worse is that such provisions are increasing. Although the juvenile criminal record is sealed, the law provides that the relevant units can inquire according to the "State regulations". If the relevant units find out the minor has been involved in the crime, then it is legal to restrict their employment. This means that once a minor becomes a criminal, he can't engage in decent, institutional and promising occupa- 
tions. On the contrary, they will be able to engage in jobs with a very small range of occupations, mostly are poor pay, temporary and manual labor-based jobs; Secondly, In the Regulations of Key Population Management, minors who had committed crimes were included in the key population. According to above provisions, public security organs can not only investigate, inquire, monitor the key population at any time, but also they need to regularly investigate, gain their relevant information in the community. And the above behavior will make minors not get rid of the shadow of the past, but also disclose a large amount of information; Finally, minors are at a critical stage of learning knowledge and skills, but at present the improper provisions of some educational institutions in China, even if the criminal record of minors is sealed, further education are still seriously affected.

\section{3) Mechanical sealed mode}

What is called "mechanical" sealed mode is mainly include three points: First of all, minors currently involved in crimes only need to meet two elements, then their criminal records can be directly sealed. Firstly, the age element: under 18 years old; Secondly, the element of penalty: sentenced to imprisonment for a term not exceeding 5 years. There is no need to consider the nature of the crime, whether the minor is a first-time offender or recidivism. Secondly, there is no probationary period, once the requirements are satisfied, their criminal records will immediately be sealed; there is no need to consider whether the minor's misconduct is corrected, whether there is still greater personal danger and social danger. The juvenile sealed criminal record system was established to help minors integrate smoothly into society, to be able to achieve substantive equality without discrimination in employment, school enrolment, etc. However, in fact the result of the above provisions is tantamount to condone the criminal behavior of minors, imagine that if the criminal records of minors who are unrepentant, have a high risk of life and are more likely to repeat an offense are sealed, they will not only fail to correct their bad behavior, but will also pose a serious potential threat to social order. More serious will lead minors to be emboldened by crime, believing that even if they commit a crime, it has no effect on themselves. In judicial practice, there are many cases which minors are repeatedly commit crimes; thirdly, the model of seal under authority. As long as the requirements of seal are met, the judicial organs initiate the seal directly. There are some problems with such a pattern. The sealed criminal record system was established in 2012. For cases completed before December 31, 2012, if they meet the requirements for seal, whether they should be sealed. According to the purpose of seal and the provisions of relevant laws, the seal of Criminal records has retrospective force. However, fewer judicial authorities seal the previously criminal record. The media also reported that some people cannot find job, because of their criminal records. When the sealed criminal record System was established, they thought they could find a job, but found that the system did not apply to themselves, so that the ideal job repeatedly lost. At present, only the model of the seal under authority is difficult to solve the above situation, the judicial 
organs generally face pressure of many cases, and procedure of seal is cumbersome, only relying on the judiciary to carry out the seal is difficult to achieve the goal.

\section{Exploration and Correction of Mistaken Ideas at the Conceptual Level}

\section{1) From "social segregation" to "social acceptance"}

The system of juvenile sealed criminal record reflects the special concern of minors in our country, and its core essence is "social acceptance". At present, many regulations in our country still embody the idea of "social segregation". By prohibiting criminals from engaging in specific occupations and discriminating in administrative management, so as to maintain the order of society. The above approach is tantamount to letting the minor enter into another more frightening cage. However, compared with adults, minors are immature in physical and mental development and are in a weak and passive position. If we still blindly label them criminals, they will not only be regarded as normal members of society, but will also be excluded and alienated, and even actively gather people with the same label. In addition, due to the limitation of the employment qualifications of citizens with criminal records, and obstacles in returning to school, it will lead them repeat crime. The above restrictions on minors are a form of discrimination in employment and education. The Constitution of our country expressly provides that "Everyone is equal before the law". Equality here is not only in the form, but also in the essence, and based on the particularity of minors, only by giving them special care can narrow the gap. In addition, our Constitution also provides that the right and duty of citizens to education and the right and duty of citizens to work. Education is an indispensable means for the formation and development of a citizen's personality, especially for minors. And the right of citizens to work is the basic guarantee for a person to obtain a happy and stable life. It can be summed up from the provisions of the Constitution that minors deserve equal rights to education and labor opportunities after their criminal records have been sealed. The state should take positive measures to ensure that minors involved in crimes can gain equal opportunities for development and facilitate them reintegrate into society.

\section{2) Balancing "the interests of minors" with "public safety"}

The sealed criminal record system is different from the system of criminal record elimination. The former refers to strictly restricting the access, reproduction and transfer of criminal record through technical operation, so that the influence of criminal record on minors can be kept within a certain range. In other words, even after the record has been sealed, the perpetrator cannot reconvert his/her normal legal status. However, the elimination of criminal record is a criminal system which reconverts the perpetrator normal legal status by eliminating the legal facts. The reason why China chooses the juvenile sealed criminal record system without directly choosing the extermination system is based on the balance of value between "minor interests" and "public safety". Particularly, 
the high crime rate among minors in recent years, the frequency of violence in schools and the increasing degree of malignancy, the younger age and the serious level of violence, citizens worry about all these things. Many citizens are even terrified of juvenile delinquency, arguing that the age of criminal responsibility for minors should be lowered and the penalties imposed on the minor should be increased. It was true that the interests of minors should be considered, but the interests of innocent victims and other citizens also required attention. The best option, therefore, must be to seal the criminal record of the minors on the basis of the rehabilitation of them. At present, the mechanical sealed mode of our country cannot implement the principle of maximizing the interests of minors, on the other hand, it cannot solve the problem of public security. First of all, if we do not take the probationary period, we will eventually seal the criminal records of the minors who have not been corrected, neither can we help them return to society, or may make them fearless of commit crimes again, thus ultimately destroying their future. The original intention of the sealed criminal record is to provide young persons an opportunity to begin their adult lives without the stigma of a juvenile record, and to become a law-abiding member of society. Therefore, the true function can achieve if juvenile delinquents can seal their records immediately, and keep them sealed contingent upon successful rehabilitation (Smith, 2010). Secondly, the current system is limited to minors sentenced to a term of imprisonment of up to five years. Although minors sentenced to fixed-term imprisonment of more than five years belong to the scope of felony, their social risk and personal danger may be relatively high, and it is reasonable to exclude them for public safety, but it is not conducive to the protection of minors without giving them any opportunities regardless of circumstances. They are still minors with their particularities, and crimes are often caused by the influence of social, family and other factors. Therefore, the scope should be further expanded to transfer the elements from the penalty elements to the consideration of the nature of the crime and whether juvenile offenders have been successfully corrected. In addition, in order to ensure that qualified criminal records are sealed, the start-up mode should be improved, which combines the power-based and application-based modes. After the applicant submits the application, judge takes the above factors into account, when the requirements are met, it should be sealed.

\section{Specific Measures for the Perfection of the Sealed Criminal Record System}

\section{1) Interface with juvenile justice-related systems}

At present, there is an understanding that due to openness and social attribute of social investigation and community correction system, concessions should be made to the system of sealed criminal record. Those who hold this idea believe that, in terms of direct effects, sealed criminal record can protect minors to the maximum extent, as long as it meets the requirements prescribed by law, criminal record should be sealed, so as to quickly restore the identity of juvenile of- 
fenders as "normal persons". Under the community correction system, offenders need to abide by certain rules, such as regular reports, and insist on participating in corrective activities, such as psychotherapy, Internet addiction cessation and so on. They also need to participate in community public welfare work, such as going to nursing homes. It will take a long time to accept community correction. This slow effect is obviously not as direct as the effectiveness of the sealed criminal record system. In addition, there are many problems in social investigation system, such as confusion of investigation subject, lack of professionalism, the form and content of social investigation report is not standard, which lead to uneven quality of the social investigation report and cannot play its due value in the process of dealing with the case. However, the community correction system and social investigation system are also indispensable for the minors to achieve rehabilitation. Most of Juvenile offenders have psychological problems, social cognitive deviation, serious poor behavior and so on, if they cannot find the cause of their crimes through social investigation and correct their bad behavior through the social correction system, minors are likely to commit crimes again. Therefore, the juvenile justice system has the same purpose in order to save the juvenile delinquency and help them return to society smoothly, but there is a difference in the form and effect of each other: sealed criminal record is a negative protection system, in order to reduce or prevent the negative impact of criminal records on juveniles; The system of community correction and social investigation of minors is an active protection system, which is a dynamic legal act to help minors return to society by exploring the causes and taking corrective measures. Therefore, the author believes that the idea of abandoning one of them should be abandoned, in particular, we can alleviate the conflict between systems by improving the methods of community correction and social investigation. For example, training professionals to use scientific methods to conduct social surveys in order to improve the effectiveness of communication and community correction, and restraining informed personnel by signing confidentiality agreements, staff should pay attention to protecting the privacy of minors when carry out related activities.

\section{2) Bridging mechanisms with relevant sectors}

The sealed of criminal records involves multiple organs and complicated procedures, and bridging mechanism of relevant departments should be strengthened. Firstly, we should strengthen communication within the judiciary and avoid the situation of "one family is sealed and the other is not sealed". In judicial practice, it is often the case that the investigation authorities fail to seal the case in time because they are not informed of the judgment of the case in time. In addition, informed units such as the Department of Justice and law firms lack a sense of sealing criminal records. And if one department disclose a juvenile record, it can have a detrimental effect upon a person's ability to secure employment and positions of trust as well as his ability to avoid a life of criminality. Secondly, the establishment of a multi-sector linkage mechanism. The purpose of the establishment of the sealed criminal record system is to help minors to get 
job and further education. Therefore, it is difficult for the judiciary to achieve this value alone. Effective cooperation mechanism must be formed with administrative, civil affairs, education, labor and other departments. A better way is to draw up documents among different departments, strengthen coordination and communication, clarify their respective responsibilities, and form a pattern of mutual cooperation, interconnection and co-management.

\section{3) A full range of crime information protection mechanisms}

From the perspective of protecting minors to the greatest extent, the information of juvenile delinquency should be kept confidential in time and all-round way, so as to reduce the negative impact of information disclosure.

Specifically, on the one hand, improving the professionalism of judicial worker, conditional areas should set up independent, professional institutions to deal with cases of minors, selecting appropriate working methods, reducing the spread of information. Secondly, the self-discipline of judicial staff should be strengthened. Judicial organs should avoid contacts with the media, perform the duty of confidentiality to the contents of cases, and prohibit disclose to the media. On the other hand, the regulation of media coverage should be strengthened. Media coverage will have a devastating impact on the disclosure of criminal information about juvenile delinquency. After reporting, no value will be generated even if sealed. To this end, we should start from the following aspects: first, media should adhere to the principle of maximizing the interests of children when reporting cases of minors, follow the principle of minimum harm; and second, give judges discretionary restrictions on the judicial coverage of minors, which should, of course, weigh the rights and interests of minors and the public interest in a specific way; third, strengthen the regulation of new media. Weibo, WeChat, QQ, everyone and other listed new social ways make it difficult to pre-control the release of case information, after the release of a large amount of information; it is difficult to solve this problem. The law should strengthen the regulation, which can require network platform service providers to assume corresponding legal responsibility to urge their supervision responsibility.

4) Establishing a systematic mechanism for registration of criminal in-

\section{formation}

At present, there are many systems to record criminal information in China, which are easy to appear storage loopholes, in addition, crime information should also be recorded as household registration files and personnel files. Compared to the former, the latter is not confidentiality, easy to leak and will seriously affect the minor's education, employment. Therefore, it is necessary for our country to establish a comprehensive and systematic special registration mechanism for criminal information. After establishment of the unified system, any records available for public inquiries, including personnel files, household registration, etc., shall not record the criminal information of minors, and minors need not fill in the circumstances of past crimes in their studies and employment. The relevant departments shall not record their crimes when recom- 
mending employment and issuing relevant certification documents; Secondly, after the establishment of the unified crime system, we should establish a review and approval mechanism and a strict information inquiry system. In order to avoid improper disclosure of information, we should set up special person responsible for inquiry; Third, clarify the confidentiality mechanism after inquiry. The unit or individual that inquires for information shall record it and sign a confidentiality agreement in writing, informing the legal liability that will be borne if the information of minors is leaked at will.

\section{5) Fulfill the obligation of informing the sealed criminal record}

The juvenile sealed criminal record system is a right granted to minors by law. As the relevant legal stipulations are too principled and inattentive, whether minors should be informed that their criminal record has been sealed, and be explained the meaning of the seal varies greatly among different district. In fact, for various reasons, most minors may not be aware of their records have been sealed. Coupled with a lack of legal knowledge, even if they know their criminal record was sealed, it is not clear what the significance and impact of the sealed criminal records system will be. The author believes that if we do not inform minors that their criminal record has been sealed and the significance of sealing, it will not be conducive for minors to return to society. When looking for a job, the employer will ask the minor if they have ever been involved in the crime, the minor is often so honest that they will tell the truth .Then probably they will lose the opportunity to get a job. What's worse, some juvenile offenders will choose to give up their future. Because they thought they will never be able to rid themselves of that stigmatizing label really have just one option: to accept it. In accepting the delinquency label, the minor learns the role and norms of the label and acts accordingly (Smith, 2010). One important aspect of the explanation should be that the juvenile offenders with a sealed record may answer inquiries that he had never been arrested or commit crime. This has been critiqued by several people as a lie. But it is in the best interests of our society that these young persons be given a clean slate when they start their adult lives. Especially given our awareness of the ways in which records are misused, the best solution is to sealed the record and to deny that it ever existed (Edwards \& Sagatun, 1976). Therefore, the author believes that the judicial authorities should inform minors whether their criminal records are sealed and the consequences of it.

\section{Conclusion}

The particularity of minors determines that they should be treated in an independent approach in criminal proceedings. When judicial organs deal with juvenile delinquency, they should emphasize the well-being of juveniles and implement the principle of maximizing the interests of children. Our country aims to help minors return to society smoothly by setting up the system of keeping criminal records, but it is a huge and complex project for minors to return to society. Only by relying on the current principles is difficult to achieve this goal. If 
the juvenile sealed criminal record System wants to play its due effect, it should not only connect with the corresponding system, but also need to establish a connection with the correction and rehabilitation of minors, so as to achieve the protection of minors while taking the interests of society into accounts.

\section{Funded}

This research is a part of project funded by Ministry of Justice (14SFB30018; sixing cuo an bijiao yanjiu).

\section{Conflicts of Interest}

The authors declare no conflicts of interest regarding the publication of this paper.

\section{References}

Beccaria, C. B. (1738-1794) (2017). On Crimes and Punishment (Huang feng, Trans.). Beijing: The Commercial Press (Original Work Published 1764).

https://doi.org/10.4324/9781315125527

Edwards, L. \& Sagatun, L. J. (1976). A Study of Juvenile Record Sealing Practices in California. Pepperding Law Review, 4, 571.

Lapp, K. (2106). American Criminal Record Exceptionalism. Ohio State Journal of Criminal Law, 14, 303.

Selbin, J., McCrary, J., \& Epstein, J. (2018). Unmarked: Criminal Record Clearing and Employment Outcomes. Journal of Criminal Law and Criminology, 108, 1.

Smith, E. (2010). Sealing up the Problem of California's One Strike and You're Out Approach for Serious Juvenile Offenders. Thomas Jefferson Law Review, 32, 362-370.

Wieder, N. (2014). Sealing the Record: An Analysis of Jurisdictional Variations of Juvenile Sex Offender Record Sealing Laws. Health Matrix, 24, 398.

Zhao, B. Z. (2011). A Study on the Criminal Responsibility of Juvenile Delinquency. Journal of Shandong Public Security College, 3, 12. 